\title{
Thyroid Peroxidase Antibodies in Non-Interferon Treated Hepatitis C Patients in Pakistan
}

\author{
Muhammad Imtiaz Shafiq, ${ }^{1,2}$ Amna Gauhar, ${ }^{2}$ Muhammad Akram, ${ }^{3}$ and Shan Elahi ${ }^{4}$ \\ ${ }^{1}$ Institute of Biochemistry and Biotechnology, University of the Punjab, Lahore 54590, Pakistan \\ ${ }^{2}$ Institute of Chemistry, University of the Punjab, Lahore 54590, Pakistan \\ ${ }^{3}$ Department of Biochemistry, SFINHS, Shaikh Zayed Postgraduate Medical Institute, Lahore, Pakistan \\ ${ }^{4}$ Centre for Nuclear Medicine (CENUM), Mayo Hospital, Lahore 54000, Pakistan
}

Correspondence should be addressed to Muhammad Imtiaz Shafiq; imtiazshafiq@gmail.com

Received 16 July 2015; Accepted 11 October 2015

Academic Editor: Dimitrios P. Bogdanos

Copyright (C) 2015 Muhammad Imtiaz Shafiq et al. This is an open access article distributed under the Creative Commons Attribution License, which permits unrestricted use, distribution, and reproduction in any medium, provided the original work is properly cited.

\begin{abstract}
Objective. Interferon therapy of HCV infected patients is associated with development of thyroid dysfunctions. Patients with pretreatment presence of antithyroid peroxidase (TPO-Ab) are at greater risk. This study, probably the first in Pakistan, was planned to determine TPO-Ab in sera of treatment-naive local HCV patients. Setting. Centre for Nuclear Medicine (CENUM), Mayo Hospital, Lahore. Patients and Methods. During July to December 2012, 190 patients (140 females, 50 males) newly diagnosed for HCV infection were selected for this study. Their age range was 15-55 years (mean: 35.3 \pm 9.1 years). 262 age matched healthy subjects (211 females and 50 males) were recruited as control. Serum-free thyroxin $\left(\mathrm{FT}_{4}\right)$ and thyroid stimulating hormone (TSH) were detected by radioimmunoassay techniques. Serum TPO-Ab titer was determined by ELISA method using commercial kits. Results. Serum $\mathrm{FT}_{4}$ and TSH levels in HCV patients and controls were within normal range. Between two groups there was no significant difference in mean value of $\mathrm{FT}_{4}(16.0 \pm 3.0$ versus $16.2 \pm 3.9 ; P=0.619)$ but mean TSH value was significantly lower in HCV patients $(1.5 \pm 0.8$ versus $1.8 \pm 0.9 ; P=0.003)$. Among HCV patients $51(26.8 \%)$ were TPO-Ab positive and among control subjects 18 (6.9\%) were TPO-Ab positive. The difference was statistically significant $(P<0.001)$. Further analysis showed that among HCV patients $39(27.8 \%)$ females and $12(24.0 \%)$ males were TPO-Ab positive, respectively, and difference was not statistically significant $(P=0.873)$. Moreover, TPO-Ab positive patients were older and had significantly higher serum TSH as compared to TPO-Ab negative HCV patients. Conclusion. Independent of patient's gender and increasing with advancing age, about one-fourth of local untreated HCV patients are TPO-Ab positive and are at greater risk of developing thyroid disorders during and after interferon treatment.
\end{abstract}

\section{Introduction}

The world epidemiology reports of hepatitis C virus (HCV) indicate that $150-200$ million people (about $3 \%$ of the world's population) are infected with HCV [1]. It is a single stranded positive RNA virus which belongs to Flaviviridae family [2]. HCV contain three structural proteins, that is, envelope 1 (E1), envelope 2 (E2), and core protein, and four nonstructural (NS) proteins, that is, nonstructural 2, 3, 4, and 5 proteins [3]. HCV causes hepatic complications that lead to chronic infection. HCV chronic infection is also related to a large number of extrahepatic manifestations including autoimmune thyroiditis [4]. Several studies suggested that hepatitis
$\mathrm{C}$ virus infection and autoimmune thyroid diseases are linked with Thl immune response [5]. It has been observed that hepatitis C viral nonstructural NS5 and structural protein core alone or with cytokines, that is, TNF- $\alpha$ and IFN- $\gamma$, provoke the upregulation of CXCL10 gene expression in the thyroid follicular cells of thyroid gland. Actually CXCL10 acts as a chemokine which attracts the lymphocytes, that is, Thl, to the site of inflammation which is caused by hepatitis $\mathrm{C}$ virus. The secretion of IFN- $\gamma$ and TNF- $\alpha$ which provokes the secretion of CXCL10 by follicular cells as a result constitutes the immune cascade leading to the induction of autoimmune thyroiditis disease in genetically susceptible patients [6]. Consequently presence of CXCL10 in hepatitis C virus patient 
is not only related to the induction of autoimmune disease but also related to a marker of violent destructions of thyrocytes in thyroid gland. The secretion of IFN- $\gamma$ by Th1 lymphocytes also triggers the apoptosis of thyroid epithelial cells [7].

In addition to autoimmune thyroiditis many other immunological abnormalities have also been reported in patients with chronic hepatitis $\mathrm{C}$ [8]. The presence of different serum autoantibodies is common in chronic HCV. These include serum nonorgan specific autoantibodies, antibodies to nuclei (ANA), smooth muscle (SMA), and liver/kidney microsomes type 1 (anti-LKM1) [8-11]. The subspecificities of these autoantibodies can be used as a diagnostic marker to distinguish between HCV and autoimmune hepatitis (AIH) [12]. It has also been reported that in some rare cases $\mathrm{HCV}$ can also manifest AIH features [13].

In Pakistan, local studies have reported thyroid dysfunction in up to $20 \%$ of $\mathrm{HCV}$ patients after IFN and ribavirin treatment $[14,15]$. However, no reports are available for the evaluation of TPO-Ab in HCV patients before interferon treatment. It may be speculated that the high incidence of TD in IFN treated patients is because of preexisting TPO$\mathrm{Ab}$ in $\mathrm{HCV}$ patients. Thus pretreatment screening for TPO$\mathrm{Ab}$ is recommended for all $\mathrm{HCV}$ patients in whom IFNa therapy is being planned. Presence of TPO-Ab need not be a contraindication to IFN-a therapy but its pretreatment evaluation may allow identifying the at-risk patients' true elucidation of thyroid dysfunction after IFN treatment in HCV patients.

The aims and objective of present study are to study the prevalence of TPO-Ab in HCV infected patients referred to CENUM. In addition this study highlight the difference in levels of thyroid function tests ( $\mathrm{FT}_{4}$ and $\mathrm{TSH}$ ) in TPO-Ab positive and negative $\mathrm{HCV}$ infected patients. The effects of gender, age, and serum TSH on prevalence of TPO-Ab in $\mathrm{HCV}$ infected patients have also been studied.

\section{Patients and Methods}

2.1. Patients' Selections. Records of all referred known hepatitis patients, aged 15-60 years, attending CENUM during July to December 2012 were reviewed. From them both female and male with normal $\mathrm{FT}_{3}$ and $\mathrm{FT}_{4}$ (euthyroid) were initially selected for this study. Among them such women who were already diagnosed with thyroid diseases and taking thyroid medications or had thyroid surgery were excluded. Similarly patients suffering from systematic diseases like diabetes mellitus and cardiac diseases were also excluded. We also excluded such patients whose record was not available. Serum samples of finally selected males and females were preserved for TPO-Ab determination. Previously these patients had undergone clinical assessment and determination of serum $\mathrm{FT}_{4}, \mathrm{FT}_{3}$, and $\mathrm{TSH}$ concentrations.

2.2. Collection of Blood Samples. An approximately $5 \mathrm{~mL}$ blood sample was taken from each patient. The blood sample was placed in centrifugation machine in order to separate the serum from blood for 5 minutes at low-speed centrifugation, that is, $2000 \mathrm{rpm}$ at room temperature.
2.3. Analysis of Serum Samples for $\mathrm{FT}_{4}, \mathrm{FT}_{3}, \mathrm{TSH}$, and TPO Antibodies. The serum samples which were obtained after centrifugation were stored at $-20^{\circ} \mathrm{C}$. Serum samples were analyzed for $\mathrm{FT}_{4}, \mathrm{FT}_{3}, \mathrm{TSH}$, and TPO antibodies. $\mathrm{FT}_{4}$ and $\mathrm{FT}_{3}$ were detected by radioimmunoassay (RIA), TSH was detected by IRMA technique, and serum TPO-Ab titer in selected patients was determined by ELISA method using commercial kit of IMMCO Diagnostics, Inc., NY, USA.

RIA and IRMA batches were run with commercially manufactured control sera at different concentrations [16, 17]. Analysis of different samples, measurement of their radioactivity, and standard curve fitting were obtained by using computerized gamma counter. Assay consistency was developed by the use of commercially manufactured control sera of high, medium, and low concentrations in each run and all assays were carried out in a duplicate manner. The results of RIA and IRMA were expressed at less than $10 \%$ $\mathrm{CV}$ of imprecision profile. Normal ranges as standardized in our laboratory for $\mathrm{FT}_{3}, \mathrm{FT}_{4}$, and TSH were $2.8-5.8 \mathrm{pmol} / \mathrm{L}$, 11-22 pmol/L, and $0.3-4.0 \mathrm{mIU} / \mathrm{L}$, respectively. The patients with TPO-Ab titer $>12.0 \mathrm{IU} / \mathrm{mL}$ were considered positive according to instructions of kit manufacturer. Microsoft Excel was used for analysis of data and chi-square test was applied for determination of the significance difference between two groups. Chi-square was applied. A $P<0.05$ value was measured for statistical significance.

\section{Results}

A total of 231 newly diagnosed $\mathrm{HCV}$ patients attended CENUM during July to December 2012. Out of 231 patients, $190(82.3 \%)$ patients had serum TSH level within normal range (0.3-4.0 mIU/L). Among them 140 were females and 50 were males. Randomly selected $262 \mathrm{HCV}$ negative subjects (211 females and 50 males) were selected as controls. All of them had normal serum $\mathrm{FT}_{4}$ and TSH (euthyroid).

The demographic and clinical characteristics of $\mathrm{HCV}$ patients and control subjects are shown in Table 1.

As compared to healthy controls, HCV infected patients were comparatively older and had low mean serum TSH. Serum TPO-Ab was determined in sera of both case and control subjects. The incidence of TPO-Ab positivity was $51(26.8 \%)$ and $18(6.9 \%)$ in $\mathrm{HCV}$ patients and control healthy subjects, respectively. The difference was statistically significant $(P<0.001)$.

Table 2 shows the comparison of demographic and clinical characteristics of TPO-Ab positive subjects between both groups of HCV patients and healthy controls. Similar to the finding reported in Table $1, \mathrm{HCV}$ infected TPO-Ab positive patients were comparatively older and had low mean serum TSH as compared to TPO-Ab positive control subjects. Among HCV patients 39 (27.8\%) females and 12 (24.0\%) males were TPO-Ab positive, respectively. The difference was not statistically significant $(P=0.873)$. Similarly among control subjects difference between female and male was not statistically significant $(P=0.969)$. To elucidate the effect of patients age and serum TSH on incidence of TPO-Ab, a comparison of TPO-Ab positive and TPO-Ab negative $\mathrm{HCV}$ 
TABLE 1: Characteristics of HCV patients and control subjects.

\begin{tabular}{lccc}
\hline & Cases & Control & $P$ value $^{*}$ \\
\hline Number $(n)$ & 190 & 200 & - \\
Mean age (year) & $35.0 \pm 9.7$ & $33.3 \pm 9.9$ & 0.083 \\
Age range (year) & $5-55$ & $18-60$ & - \\
Number of female patients & $140(73.7 \%)$ & $149(74.5 \%)$ & 0.200 \\
Number of male patients & $50(26.3 \%)$ & $51(25.5 \%)$ & 0.192 \\
Mean FT & $16.0 \pm 3.0$ & $16.0 \pm 2.3$ & 0.981 \\
Mean TSH & $1.5 \pm 0.8$ & $1.7 \pm 0.9$ & 0.091 \\
TPO-Ab positive & $51(26.8 \%)$ & $17(8.5 \%)$ & 0.0001 \\
\hline
\end{tabular}

${ }^{*} P$ value $=$ it explains the probability of incidence of given event.

TABLE 2: Effect of HCV patient factors on TPO-Ab positivity.

\begin{tabular}{lccc}
\hline & Group & TPO-Ab+ & $P$ value \\
\hline \multirow{2}{*}{ Gender } & Female $(n=140)$ & $39(27.8 \%)$ & 0.873 \\
& Male $(n=50)$ & $12(24.0 \%)$ & \\
\hline \multirow{2}{*}{ Age } & $\leq 35 \mathrm{Y}(n=102)$ & $24(23.5 \%)$ & \multirow{2}{*}{0.536} \\
\hline \multirow{2}{*}{ TSH } & $>35 \mathrm{Y}(n=88)$ & $27(30.7 \%)$ & \\
& $<2.5(n=161)$ & $39(24.2 \%)$ & 0.161 \\
\hline
\end{tabular}

TABLE 3: Comparison of TPO-Ab positive and TPO-Ab negative HCV patient.

\begin{tabular}{lccc}
\hline \multirow{2}{*}{ Characteristics } & \multicolumn{2}{c}{ Group } & \multirow{2}{*}{$P$ value* } \\
& TPO-Ab positive & TPO-Ab negative & \\
\hline Number $(n)$ & 51 & 139 & \\
Mean age (year) & $37.8 \pm 9.2$ & $34.3 \pm 9.6$ & 0.027 \\
Mean $\mathrm{FT}_{4}(\mathrm{pmol} / \mathrm{L})$ & $15.6 \pm 2.8$ & $16.1 \pm 3.0$ & 0.348 \\
Mean TSH & $1.8 \pm 0.9$ & $1.4 \pm 0.7$ & 0.012 \\
\hline
\end{tabular}

${ }^{*} P$ value $=$ it explains the probability of incidence of given event.

patients is shown in Table 3. TPO-Ab positive patients were significantly older and had higher serum TSH as compared to TPO-Ab negative patients. In summary, incidence of TPO-Ab positivity among HCV patients is $26.8 \%$ which is significantly higher as compared to healthy adult population. TPO-Ab positivity is independent of HCV patient gender but is higher in patients with advanced age and raised serum TSH.

\section{Discussion}

The aim of this study was to know the prevalence of TPO-Ab in euthyroid HCV patients referred to CENUM, Mayo Hospital, for thyroid function testing before interferon treatment. In a selected data set of HCV patients the incidence of TPO$\mathrm{Ab}$ was detected in 51 (26.8\%). Other studies have reported TPO-Ab prevalence in $2 \%$ to $30 \%$ of non-interferon treated HCV patients [18-21]. Present study results are in accordance to Yang et al. (2011) who reported TPO-Ab prevalence in $30.8 \%$ of HCV patients before INF-a treatment [20]. The prevalence of TPO-Ab in $21 \%$ of patients has also been reported in HCV infection [21]. The incidence of TPO-Ab positivity was significantly higher $(P<0.0001)$ as compared to healthy euthyroid adult population that had incidence of $6.9 \%$. This is in accordance with recent studies [21, 22] but some older studies do not support this finding [23, 24]. The difference may be due to improvement in laboratory diagnosis of thyroid autoantibodies.

Different studies have proposed several mechanisms for induction of autoimmune thyroiditis by HCV infection like molecular mimicry between viral antigens and self-antigens, activation of autoreactive $\mathrm{T}$ cells (bystander mechanism) by induction of local inflammation, induction of aberrant expression of MHC class II molecules on thyroid cells, viral induction of changes in self-antigen expression of cryptic epitopes, and induction of heat-shock proteins in the thyroid $[4,25,26]$. On the other hand, the HCV inducing the thyroid autoimmunity in predisposed individual are still mysterious. Among abovementioned mechanisms, two hypotheses, that is, molecular mimicry and bystander activation, have strongest indication of development of thyroid autoimmunity in hepatitis $\mathrm{C}$ virus patients. The molecular mimicry hypothesis suggested that sequence of nucleotides similar between self-proteins and viral proteins can cause a cross over immune reaction to self-antigens which are imitated by “infectious agents" proteins $[26,27]$. Though HCV could not transmit a virus to thyrocytes (thyroid gland cells), coat of virus which is basically a protein also influenced the other body parts because it has a significant physiological effects. For instance, two HCV structural proteins, that is, E1 and E2, have a capability to bind with certain body surface molecules, that is, CD81, which help in viral entry [27]. According to bystander activation hypothesis, local inflammation is induced by viral infection; as a result, stimulation of autoreactive T lymphocytes occurs which were repressed by Treg cells (regulatory T cells) through peripheral tolerance mechanisms [27]. Recent facts support the bystander activation process as the crucial method by which hepatitis $C$ virus induces autoimmune thyroiditis. Consequently, it is proved that the relation among thyroid autoimmunity and hepatitis $C$ virus infection is caused by HCV infection of the thyroid as a result of proinflammatory mediators release, such as IL-8, and development of thyroid autoimmunity through bystander activation process [4].

Thyroid autoimmunity is enhanced in female as compared to male subjects [28]. The similar trend is reported in HCV infected patients by different studies [20, 29]. However, according to recent study results between $\mathrm{HCV}$ patients $39(27.8 \%)$ and $12(24.0 \%)$ females and males were TPOAb positive, respectively. The difference was not statistically significant $(P=0.873)$. Similarly among control subjects difference between female and male was not statistically significant $(P=0.969)$. Thus TPO-Ab positivity was independent of patient's gender. This is in accordance with some studies $[19,30]$ but most studies have reported more incidence of TPO-Ab in female as compared to male HCV patients [18, 22, 31]. Similarly, Hass et al. (2009) detected significantly more abnormal pretreatment TSH levels (TSH $>3.0 \mathrm{mU} / \mathrm{L}$ or $<0.4 \mathrm{mU} / \mathrm{L}$ ) in female patients and Testa et al. (2006) reported almost double incidence of hypothyroidism in female as compared to male patients $[32,33]$. The apparent reason for disagreement between our study and other studies 
may be the difference in patients' selection method. TPOAbs were determined in referred HCV patients while other studies had recruited HCV positive patients without considering signs and symptoms of thyroid dysfunction. Higher incidence of TPO-Ab positivity in patients with advanced age is observed in both HCV patients and control and the same trend was also found in TPO-Ab positive $\mathrm{HCV}$ patients when compared with TPO-Ab positive controls. This is in accordance with another study [22]. A similar study like ours also noted a higher incidence of TPO-Ab positivity in patients presenting with raised serum TSH.

\section{Conclusion}

Thyroid gland dysfunction has been reported to occur with variable frequency during Interferon Alfa $(\mathrm{IFN}-\alpha)$ therapy in TPO-Ab positive patients with the hepatitis $\mathrm{C}$ virus (HCV) [34]. The results of such studies conducted locally should be interpreted in the light of our results where $25 \%$ of HCV infected patients have TPO-Ab before this treatment and such patients are at increased risk of developing thyroid dysfunction after Interferon Alfa (IFN- $\alpha$ ) therapy.

\section{Conflict of Interests}

The authors declare no conflict of interests.

\section{References}

[1] E. Gower, C. Estes, S. Blach, K. Razavi-Shearer, and H. Razavi, "Global epidemiology and genotype distribution of the hepatitis C virus infection," Journal of Hepatology, vol. 61, no. 1, pp. S45S57, 2014.

[2] A. G. Khan, M. T. Miller, and J. Marcotrigiano, "HCV glycoprotein structures: what to expect from the unexpected," Current Opinion in Virology, vol. 12, pp. 53-58, 2015.

[3] F. Penin, J. Dubuisson, F. A. Rey, D. Moradpour, and J.-M. Pawlotsky, "Structural biology of hepatitis C virus," Hepatology, vol. 39, no. 1, pp. 5-19, 2004.

[4] N. Akeno, J. T. Blackard, and Y. Tomer, "HCV E2 protein binds directly to thyroid cells and induces IL-8 production: a new mechanism for HCV induced thyroid autoimmunity," Journal of Autoimmunity, vol. 31, no. 4, pp. 339-344, 2008.

[5] W. Sun, Q. Li, D. Zhu et al., "Enhancement of immune response to a hepatitis $\mathrm{C}$ virus E2 DNA vaccine by an immunoglobulin Fc fusion tag," Journal of Medical Virology, vol. 87, no. 12, pp. 2090-2097, 2015.

[6] A. Antonelli, P. Fallahi, S. M. Ferrari et al., "Circulating CXCL11 and CXCL10 are increased in hepatitis C-associated cryoglobulinemia in the presence of autoimmune thyroiditis," Modern Rheumatology, vol. 22, no. 5, pp. 659-667, 2012.

[7] S. H. Wang, J. D. Bretz, E. Phelps et al., "A unique combination of inflammatory cytokines enhances apoptosis of thyroid follicular cells and transforms nondestructive to destructive thyroiditis in experimental autoimmune thyroiditis," The Journal of Immunology, vol. 168, no. 5, pp. 2470-2474, 2002.

[8] F. Cassani, M. Cataleta, P. Valentini et al., "Serum autoantibodies in chronic hepatitis C: comparison with autoimmune hepatitis and impact on the disease profile," Hepatology, vol. 26, no. 3, pp. 561-566, 1997.
[9] N. Abuaf, F. Lunel, P. Giral et al., "Non-organ specific autoantibodies associated with chronic C virus hepatitis," Journal of Hepatology, vol. 18, no. 3, pp. 359-364, 1993.

[10] L. Todros, G. Touscoz, N. D’Urso et al., "Hepatitis C virusrelated chronic liver disease with autoantibodies to liver-kidney microsomes (LKM): clinical characterization from idiopathic LKM-positive disorders," Journal of Hepatology, vol. 13, no. 1, pp. 128-131, 1991.

[11] L. Todros, G. Saracco, M. Durazzo et al., "Efficacy and safety of interferon alfa therapy in chronic hepatitis $\mathrm{C}$ with autoantibodies to liver-kidney microsomes," Hepatology, vol. 22, no. 5, pp. 1374-1378, 1995.

[12] L. Muratori, M. Lenzi, Y. Ma et al., "Heterogeneity of liver/ kidney microsomal antibody type 1 in autoimmune hepatitis and hepatitis C virus related liver disease," Gut, vol. 37, no. 3, pp. 406-412, 1995.

[13] Z. Michalska, P. Stalke, K. Witczak-Malinowska et al., "Autoimmune reactions in HBV and HCV," Medical Science Monitor, vol. 7, pp. 175-180, 2001.

[14] A. Nadeem, M. Aslami, D. A. Khan, T. Hussain, and S. A. Khan, "Effects of combined interferon alpha and ribavirin therapy on thyroid functions in patients with chronic hepatitis C," Journal of the College of Physicians and Surgeons Pakistan, vol. 19, no. 2, pp. 86-89, 2009.

[15] N. Masood, R. Ghori, A. Memon et al., "Frequency of thyroid disorders during interferon and ribavirin therapy in chronic hepatitis C infection," Journal of the College of Physicians and Surgeons Pakistan, vol. 18, no. 6, pp. 347-351, 2008.

[16] I. J. Chopra, "A radioimmunoassay for measurement of $3,3^{\prime}, 5^{\prime}$ triiodothyronine (reverse T3)," The Journal of Clinical Investigation, vol. 54, no. 3, pp. 583-592, 1974.

[17] E. Martino, G. Bambini, L. Bartalena et al., "Human serum thyrotrophin measurement by ultrasensitive immunoradiometric assay as a first-line test in the evaluation of thyroid function," Clinical Endocrinology, vol. 24, no. 2, pp. 141-148, 1986.

[18] A. Tran, J.-F. Quaranta, S. Benzaken et al., "High prevalence of thyroid autoantibodies in a prospective series of patients with chronic hepatitis C before interferon therapy," Hepatology, vol. 18 , no. 2, pp. 253-257, 1993.

[19] E. Zusinaite, K. Metsküla, and R. Salupere, "Autoantibodies and hepatitis $\mathrm{C}$ virus genotypes in chronic hepatitis $\mathrm{C}$ patients in Estonia," World Journal of Gastroenterology, vol. 11, no. 4, pp. 488-491, 2005.

[20] Y. Yang, Y. Kuang, Y. Liu et al., "Immunogenicity of multipleepitope antigen gene of HCV carried by novel biodegradable polymers," Comparative Immunology, Microbiology and Infectious Diseases, vol. 34, no. 1, pp. 65-72, 2011.

[21] A. Antonelli, C. Ferri, P. Fallahi et al., "Thyroid involvement in patients with overt HCV-related mixed cryoglobulinaemia," QJM, vol. 97, no. 8, pp. 499-506, 2004.

[22] N. Ganne-Carrie, A. Medini, E. Coderc et al., "Latent autoimmune thyroiditis in untreated patients with HCV chronic hepatitis: a case-control study," Journal of Autoimmunity, vol. 14, no. 2, pp. 189-193, 2000.

[23] J. Boadas, J. Rodríguez-Espinosa, J. Enríquez et al., "Prevalence of thyroid autoantibodies is not increased in blood donors with hepatitis C virus infection," Journal of Hepatology, vol. 22, no. 6 , pp. 611-615, 1995.

[24] R. A. Metcalfe, G. Ball, G. Kudesia, and A. P. Weetman, "Failure to find an association between hepatitis $\mathrm{C}$ virus and thyroid autoimmunity," Thyroid, vol. 7, no. 3, pp. 421-424, 1997. 
[25] Z. Jadali, "Autoimmune thyroid disorders in hepatitis $C$ virus infection: effect of interferon therapy," Indian Journal of Endocrinology and Metabolism, vol. 17, no. 1, p. 69, 2013.

[26] L. Muratori, D. P. Bogdanos, P. Muratori et al., "Susceptibility to thyroid disorders in hepatitis C," Clinical Gastroenterology and Hepatology, vol. 3, no. 6, pp. 595-603, 2005.

[27] Y. Tomer and A. Huber, "The etiology of autoimmune thyroid disease: a story of genes and environment," Journal of Autoimmunity, vol. 32, no. 3-4, pp. 231-239, 2009.

[28] C. C. Whitacre, "Sex differences in autoimmune disease," Nature Immunology, vol. 2, no. 9, pp. 777-780, 2001.

[29] V. Themistoklis, A. Panagiotis, N. Georgios et al., "Thyroid dysfunction and long-term outcome during and after interferonalpha therapy in patients with chronic hepatitis C," Annals of the Academy of Medicine, Singapore, vol. 40, no. 9, pp. 394-400, 2011.

[30] M.-J. Huang, S.-L. Tsai, B.-Y. Huang, I.-S. Sheen, C.-T. Yeh, and Y.-F. Liaw, "Prevalence and significance of thyroid autoantibodies in patients with chronic hepatitis $\mathrm{C}$ virus infection: a prospective controlled study," Clinical Endocrinology, vol. 50, no. 4, pp. 503-509, 1999.

[31] M. Marazuela, L. García-Buey, B. González-Fernández et al., "Thyroid autoimmune disorders in patients with chronic hepatitis C before and during interferon-alpha therapy," Clinical Endocrinology, vol. 44, no. 6, pp. 635-642, 1996.

[32] A. Testa, P. Castaldi, V. Fant et al., "Prevalence of HCV antibodies in autoimmune thyroid disease," European Review for Medical and Pharmacological Sciences, vol. 10, no. 4, pp. 183186, 2006.

[33] H. G. Hass, R. Klein, O. Nehls, and S. Kaiser, “Thyroid disorders and occurrence of Nonorgan-Specific Autoantibodies (NOSA) in patients with chronic hepatitis $\mathrm{C}$ before and during antiviral induction therapy with consensus interferon (interferon alfacon-1)," Journal of Clinical Gastroenterology, vol. 43, no. 5, pp. 470-476, 2009.

[34] Y. Nagayama, K. Ohta, M. Tsuruta et al., "Exacerbation of thyroid autoimmunity by interferon $\alpha$ treatment in patients with chronic viral hepatitis: our studies and review of the literature," Endocrine Journal, vol. 41, no. 5, pp. 565-572, 1994. 


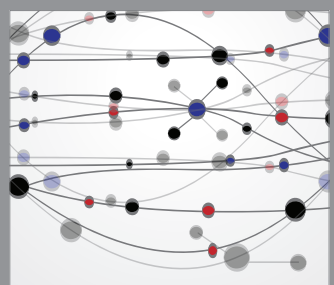

The Scientific World Journal
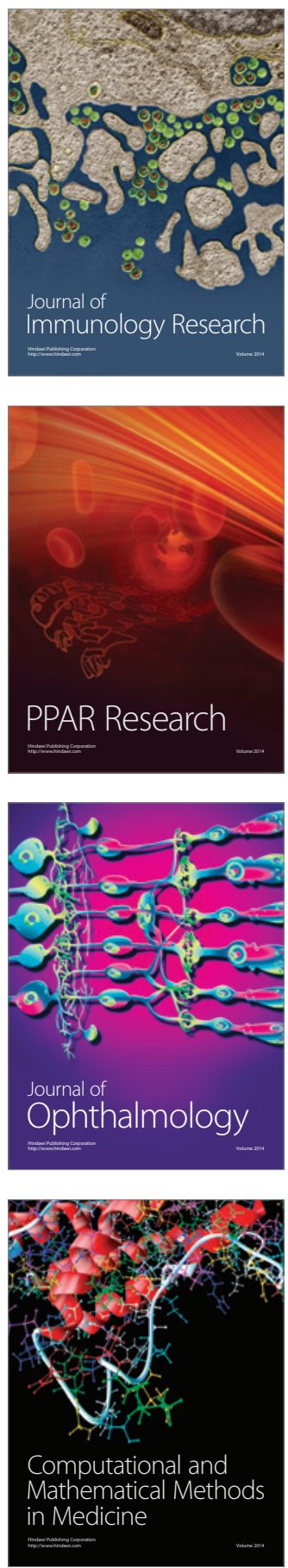

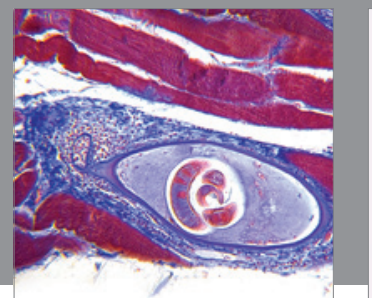

Gastroenterology

Research and Practice
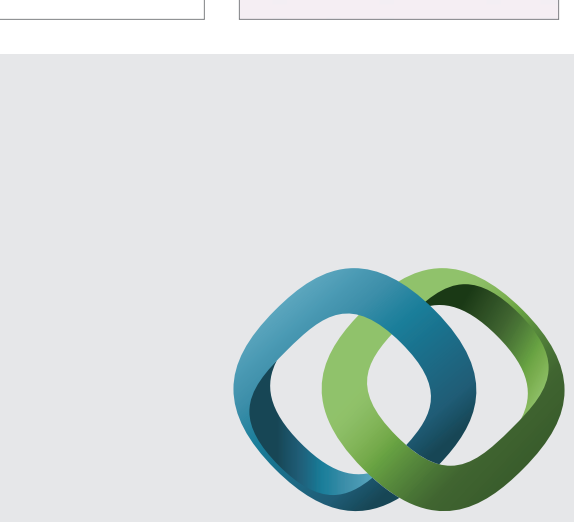

\section{Hindawi}

Submit your manuscripts at

http://www.hindawi.com
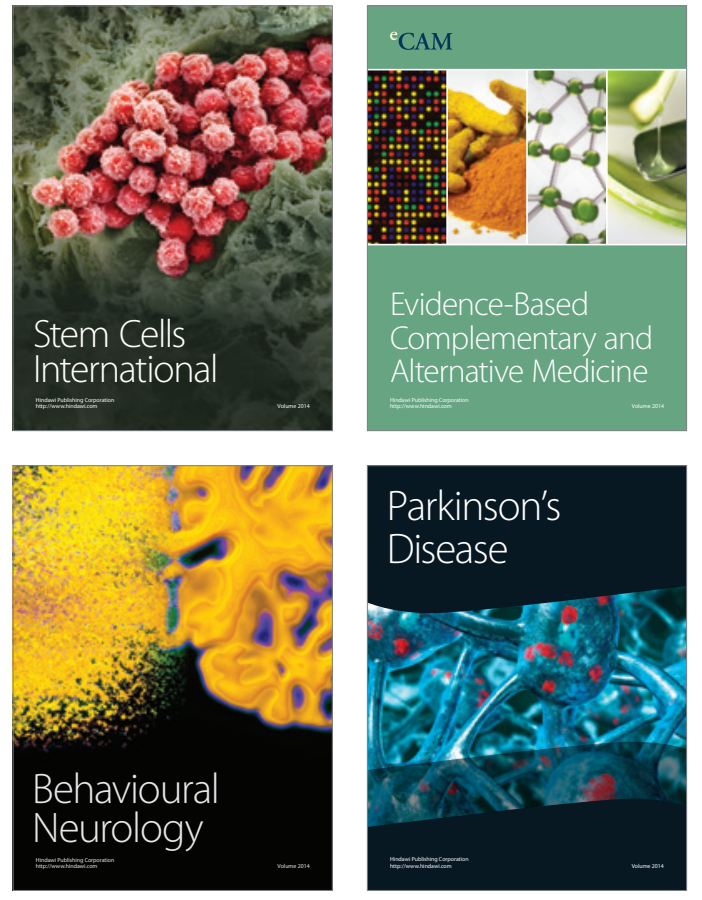
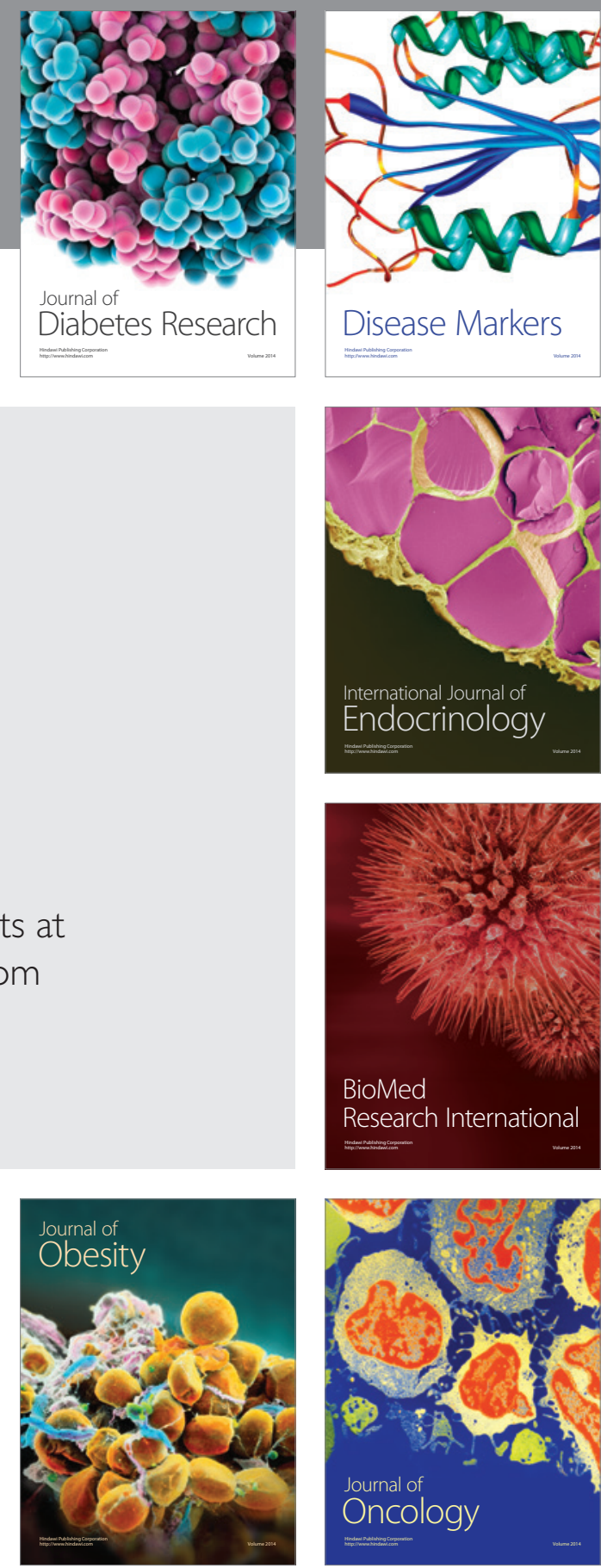

Disease Markers
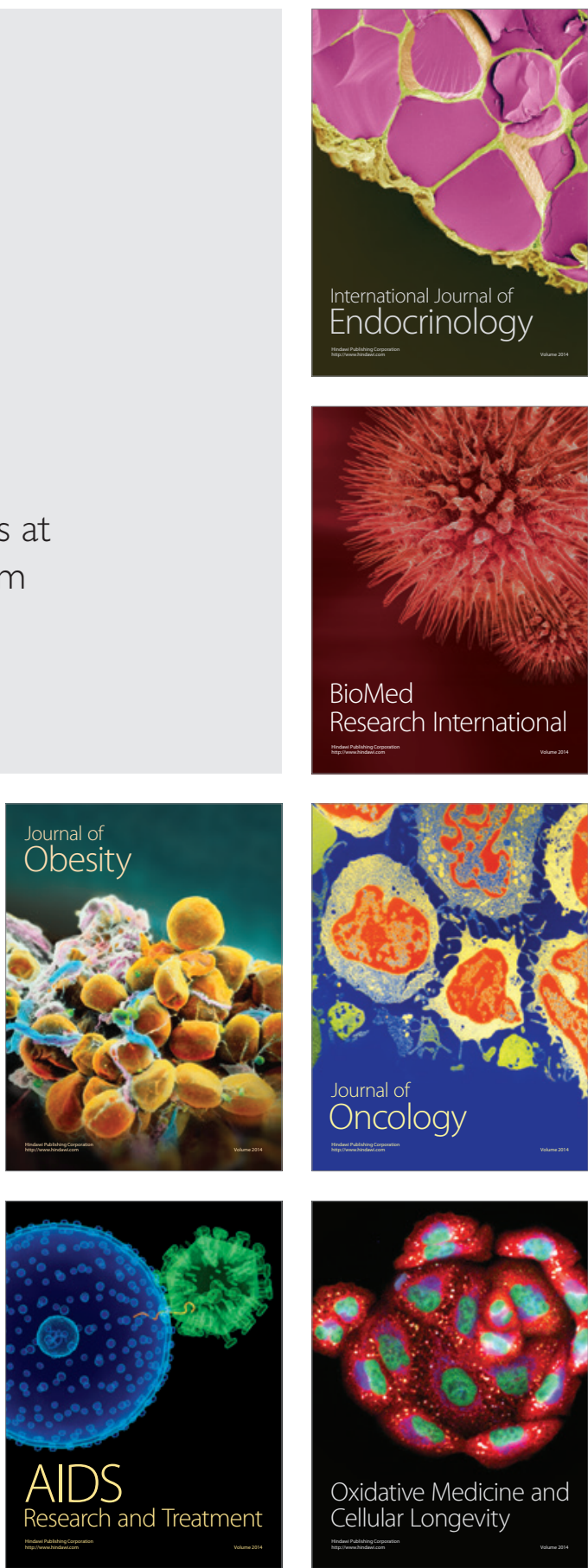